\title{
Which product would be chosen? A fuzzy VIKOR method for evaluation and selection of products in terms of customers' point of view; Case study: Iranian cell phone market
}

\author{
Jahangir Yadollahi Farsi $^{\mathbf{a}}$, Javad Siahkali Moradi ${ }^{\mathbf{b}^{*}}$ and Behrooz Jamali ${ }^{\mathrm{c}}$
}

${ }^{a}$ Associate Professor, Entrepreneurship Management, University of Tehran, Tehran, Iran
${ }^{b}$ Operational Research, Science and Research Branch, Islamic Azad University, Tehran, Iran
${ }^{c}$ MS in Entrepreneurship Management, University of Tehran, Tehran, Iran

A R T I C L E I N F O AB S T A T

Article history:

Received March 29, 2012

Accepted 18 June 2012

Available online

June 222012

Keywords:

Product Selection

Marketing

Cell phone evaluating criteria

Fuzzy set

VIKOR method

\begin{abstract}
Product selection is always one of the troubles that decision makers are facing with it. Correct selection requires having suitable method for this important issue. In this article, we concern to introduce an approach of fuzzy decision making for selection to decision makers. The nature of decision making is usually complex and without structure. Totally, most of qualitative and quantitative factors such as quality, price, and flexibility should be concerned for determining a suitable product. In this study, it is attempted to use recent advances in ranking methods for product selection. The proposed study uses oral preferences language shown in terms of triangular and trapezoid fuzzy numbers. Then, a multi criteria hierarchical decision making is suggested on the basis of fuzzy collection theory for product selection where the proposed fuzzy VIKOR uses different qualitative and quantitative criteria.
\end{abstract}

\section{Introduction}

The primary objective of any product selection normally involves different criteria such as risk, reliability of product, quality characteristics, warranty and guarantee features, etc. Most of vendors are also interested in offering products with good characteristics to build long-term relationships with their customers (Monczkilet al., 1998). During the past two decades, there have been tremendous efforts to provide various techniques to facilitate production selection procedure (Boer et al., 1998, Lee et al., 2001). Most of these methods do not seem to show complexity and nature of nonstructuralism and background of various decisions for daily purchase (Boer et al., 1998). In fact, most of them present decisions just only consider some the criteria for product selection.

On the other hand, several effective factors such as incomplete information, extra qualitative criteria and wrong priorities are not often accounted in the process of decision making. According to extent

\footnotetext{
* Corresponding author. Tel: +989122520885

E-mail addresses: syahkaly@yahoo.com (J. Syahkaly Moradi) 
literature of product selection (Boeret al., 1998, Choi \& Hartley, 1996, Weber et al., 1991), we conclude that some of characteristics are remarkably variable during solving problem of decision making for product selection. Firstly, it is possible that some criteria are considered in terms of qualitative dimensions where most of them are in serious conflict (Choi \& Hartley, 1996, Dolatshahi, 2000, Verma \& Pullman, 1998, Weber et al., 1991, 1998). A strategic approach about selecting product probably emphasizes mostly on necessity of multi criteria (Donaldson, 1994, Ellram, 1992, Swift, 1995).

It is also possible that several decision makers involve in the process of product selection (Boeret al., 1998). Decision making is often affected in action by incertitude situation. Numerous numbers of product selections can be arranged as dynamic and non-structuralism decisions. There are many technological advances on today's world and things changes very quickly, which makes decision making a complicated approach (Cook, 1992). Different types of decisions can be divided into compensatory or non-compensatory methods (Boer et al., 1998; Ghodsypour \& O'Brien, 1998; Roodhooft \& Konings, 1996). Compensatory methods of decision making includes efficient solutions for handling product selection. Non-compensatory methods, on the other hand, are those with a degree of an alternative change, which can be compensated in other criteria by relatively high degrees. By these issues, we can conclude that classical concept of optimism cannot always be the most suitable model in product selection (Boer et al., 1998).

Product selection probably involves several different groups of criteria, combination of various decision models, group decision making and different forms of incertitude. The best selection way for making an assessment for product selection is a complicated and difficult issue and many organizations use various techniques to handle this issue. Hence, the most important issue for the process of product selection is to improve a suitable method for selecting correct product. Product selection is principally a collaborative decision making, which needs considering different multi criteria. Degree of incertitude, number of decision makers and nature of criteria are some of the cases, which should be concerned for solving this matter. Weight of criteria is accurately and concretely recognized in the method of classic multi criteria decision making methods (Delgado et al., 1992; Hwang \& Yoon, 1981; Kaufmann \& Gupta, 1991).

Next, we show a method of fuzzy decision making for product selection and using a simple method we explain the implementation of the proposed model.

\section{Fuzzy numbers and oral variables}

In this part, several principle definitions from fuzzy collections, fuzzy numbers and oral variables are reviewed.

Definition 2.1: A subordinator with a membership $\mu_{\mathrm{A}}(\mathrm{x})$ has two amounts of zero and the structure is as follows,

$\mu_{A}(x)= \begin{cases}x \in A & 1 \\ x \notin A & 0\end{cases}$

Then a collection of Fuzzy $\widetilde{\mathrm{A}}$ is defined with its membership as the follow,

$\tilde{A}=\left\{\left(x, \mu_{\tilde{A}}(x)\right) \mid x \in A \wedge \mu_{\tilde{A}}(x) \in[\circ, 1]\right\}$

Note that a collection of fuzzy selects many amounts between zero and one. 
Definition 2.2: Fuzzy collection of $\widetilde{A}$ is convex if and just if we have:

$\mu_{\tilde{A}}\left(\lambda x_{1}+(1-\lambda) x_{2}\right) \geq \min \left(\mu_{A}\left(x_{1}\right), \mu_{A}\left(x_{2}\right)\right.$

Definition 2.3: if one of its membership attains the maximum degree one, the collection of Fuzzy $\widetilde{A}$ is said normal. Otherwise, the collection of Fuzzy is not considered normal. For making normal, relation of $\frac{\mu_{\widetilde{\AA}}(x)}{\operatorname{Max} \mu_{\widetilde{A}}(x)}$ is used.

Definition 2.4: Fuzzy number $\widetilde{n}$ is a collection of normal convex collection of $\mathrm{R}$ collection, if:

_ $\mathrm{n}_{\circ} \in \mathrm{R}$ exits and the membership subordinator of $\mu_{\tilde{n}}\left(n_{\circ}\right)=1$ and $\mathrm{n}_{\circ}$ is called the average amount of fuzzy number $\widetilde{n}$.

- Membership subordinator of $\mathrm{n}$ and $\mu_{\tilde{n}}(n)$ is continuous or blow by blow (look at Table 2 ).

Definition 2.5: Definite fuzzy collection of $\mathrm{A}_{\alpha}$ is defined on the basis of definite collection of elements of $x$ having freedom degree of $\alpha$, which belongs to $\widetilde{\mathrm{A}}$ :

$$
A_{\alpha}=\left\{x \mid x \in R \wedge \mu_{\tilde{A}}(x) \geq \alpha\right\}, \quad \alpha \in[\circ, 1]
$$

The above relationship maintains a level of acceptance, where a level of insurance of $\alpha$ is provided in a decision. In other words, $\alpha$ cut, is the collection of global collection elements where the membership subordinator is larger or equivalent with $\alpha$ and cut membership subordinator with $\alpha$, is a membership that larger $\mu$ s of $\alpha$ have been replaced with $\alpha$

Definition 2.6:

- A trapezoid fuzzy number $\tilde{n}=\left(n_{1}, n_{2}, n_{3}, n_{4}\right)$ can be defined with its membership subordinator as the follow, (Kaufman and Gopta 1991):

$\mu_{\tilde{n}}(x)= \begin{cases}0, & x<n_{1}, \\ \frac{x-n_{1}}{n_{2}-n_{1}}, & n_{1} \leq x \leq n_{2}, \\ 1, & n_{2} \leq x \leq n_{3}, \\ \frac{x-n_{4}}{n_{3}-n_{4}}, & n_{3} \leq x \leq n_{4}, \\ 0, & x>n_{4} .\end{cases}$

A sample of these numbers are given in Table 3.

- A triangular fuzzy number $\tilde{n}=\left(n_{1}, n_{2}, n_{3}\right)$ can be shown with its membership subordinator as follow, If $n_{2}=n_{3}$, then triangular fuzzy number is presented as $\tilde{\mathrm{n}}$ :

$\mu_{\tilde{n}}(x)= \begin{cases}0, & x<n_{1}, \\ \frac{x-n_{1}}{n_{2}-n_{1}}, & n_{1} \leq x \leq n_{2}, \\ \frac{x-n_{2}}{n_{3}-n_{2}}, & n_{2} \leq x \leq n_{3}, \\ 0, & x>n_{3} .\end{cases}$

Concerning two trapezoids fuzzy numbers of $\tilde{n}=\left(\mathrm{n}_{1}, \mathrm{n}_{2}, \mathrm{n}_{3}, \mathrm{n}_{4}\right)$ and $\tilde{m}=\left(\mathrm{m}_{1}, \mathrm{~m}_{2}, \mathrm{~m}_{3}, \mathrm{~m}_{4}\right)$, the following arithmetic operations are defined, 


$$
\begin{aligned}
& \tilde{m} \oplus \tilde{n}=\left[m_{1}+n_{1}, m_{2}+n_{2}, m_{3}+n_{3}, m_{4}+n_{4}\right], \\
& \tilde{m} \oplus \tilde{n}=\left[m_{1}-n_{4}, m_{2}-n_{3}, m_{3}-n_{2}, m_{4}-n_{1}\right], \\
& \tilde{m} \otimes r=\left[m_{1} r, m_{2} r, m_{3} r, m_{4} r\right], \\
& \tilde{m} \otimes \tilde{n} \cong\left[m_{1} n_{1}, m_{2} n_{2}, m_{3} n_{3}, m_{4} n_{4}\right] \\
& k \tilde{A}=\left(k a_{1}, k a_{2}, k a_{3}\right) \\
& (\tilde{A})^{-1}=\left(\frac{1}{a_{3}}, \frac{1}{a_{2}}, \frac{1}{a_{1}}\right)
\end{aligned}
$$

Definition 2.7: A matrix of $\tilde{D}$ is called fuzzy matrix; if its element have barely a fuzzy number (Buckley, 1985).

Definition 2.8: An oral variable is as denoted as an oral word.

Since oral variables are very complex, concept of an oral variable is not well defined or logically described in the conventional words, which is very useful.

For example, weight is an oral variable, where its amount can be described as very low, low, medium, high, very high and etc. Let $\widetilde{m}=\left(m_{1}, m_{2}, m_{3}, m_{4}\right)$ and $\widetilde{n}=\left(n_{1}, n_{2}, n_{3}, n_{4}\right)$ be two trapezoid fuzzy variables, then the distance between these two numbers is computed by the method of apex (Chen 2000) as follows,

$d_{v}(\tilde{m}, \tilde{n})=\sqrt{\frac{1}{4}\left[\left(m_{1}-n_{1}\right)^{2}+\left(m_{2}-n_{2}\right)^{2}+\left(m_{3}-n_{3}\right)^{2}+\left(m_{4}-n_{4}\right)^{2}\right]}$

Let $\widetilde{m}=\left(m_{1}, m_{2}, m_{3}\right)$ and $\widetilde{n}=\left(n_{1}, n_{2}, n_{3}\right)$ be two triangular fuzzy numbers, then their distance is calculated by the method of apex (Chen, 2000) as follows,

$$
d_{v}(\tilde{m}, \tilde{n})=\sqrt{\frac{1}{3}\left[\left(m_{1}-n_{1}\right)^{2}+\left(m_{2}-n_{2}\right)^{2}+\left(m_{3}-n_{3}\right)^{2}\right]}
$$

Method of apex is a simple and effective one for calculating the distance between two trapezoid fuzzy numbers. Regarding method of apex, two trapezoid fuzzy numbers of $\widetilde{m}, \widetilde{n}$ is equivalent if we have $d_{v}(\tilde{m}, \tilde{n})=\circ$.

Let $\widetilde{m}, \widetilde{n}, \widetilde{p}$ be three trapezoid fuzzy numbers. If fuzzy number $\widetilde{n}$ compared with fuzzy number $\widetilde{m}$ in compared with fuzzy number $\widetilde{p}$ and if $d_{v}(\tilde{m}, \tilde{n})<d_{v}(\tilde{m}, \widetilde{p})$ then we can say that two fuzzy numbers $\widetilde{p}$ and $\widetilde{m}$ are near to each other (Chen, 2000).

\section{Fuzzy VIKOR method}

VIKOR method was developed by Opricovic (1997) to solve MADM problems. This method focuses on prioritizing and selecting the best alternative from a set of alternatives in a problem where the criteria are in conflict (Opricovic \& Tzeng 2004). VIKOR method was introduced by Trajkovic et al. (1997). VIKOR has been developed to solve a discrete decision problem with non-commensurable and conflicting criteria (Opricovic \& Tzeng, 2004; Opricovic, 2008). The Optimization method in VIOKR is based on linear normalization. This would end in a better solution than TOPSIS method. In TOPSIS we utilize vector normalization (Tzeng et al., 2005). Another preference of using VIKOR method is that VIKOR method calculates ratio of positive and negative ideal solutions, so VIKOR method proposes a compromise solution with an advantage rate (Tzeng et al., 2005) but in TOPSIS 
method the best alternative is ranked by its distance to positive ideal solution and negative ideal solution (Chu et al., 2007). Some studies that utilized VIKOR method to solve a MADM problem are as follows:

Tong et al. (2005) employed the VIKOR method to optimize a multi response process (Tong et al., 2005). Chu et al. (2007) provided a comparison analysis of VIKOR, TOPSIS and SAW and demonstrated the overall knowledge communication achievements, showing their similarities and differences to achieve group decisions (Chu et al., 2007). Sayadi et al. (2009) analyzed the VIKOR method and extended it for MCDM problems with interval numbers and introduced optimism level of decision making (Sayadi et al., 2009). Amiri et al. (2011) applied a fuzzy VIKOR method to select the best supplier in an automotive case.

The procedure of fuzzy VIKOR consists of the following steps (Chen \& Wang, 2008):

Step 1: Generating feasible alternatives, determining the evaluation criteria, and setting a group of decision makers. Assume that there are $m$ alternatives, $k$ evaluation criteria, and $n$ decision makers.

Step 2: Define linguistic variables and their corresponding triangular fuzzy numbers. Linguistic variables are used to evaluate the importance of the criteria and the ratings of alternatives with respect to various criteria.

Let $\tilde{A}$ and $\tilde{B}$ be two triangular fuzzy numbers (TFN) parameterized by the triple $\left(a_{1}, a_{2}, a_{3}\right)$ and $\left(b_{1}, b_{2}, b_{3}\right)$, respectively the operational laws of these two triangular fuzzy numbers are as follows:

According to Chou \& Chang's (2008) studies, a seven-scale linguistic variable fuzzy number was used to access the importance of evaluation criteria with a fuzzy set. The linguistic scales and corresponding triangular fuzzy numbers for the weight of criteria and the rating of alternatives show in Table 1 and Table 2.

\section{Table 1}

Linguistic terms for the importance weights along with their relative importance

\begin{tabular}{lllllll}
\hline Very low $(\mathrm{VL})$ & Low $(\mathrm{L})$ & Medium low $(\mathrm{ML})$ & Medium $(\mathrm{M})$ & Medium high $(\mathrm{MH})$ & High $(\mathrm{H})$ & Very high $(\mathrm{VH})$ \\
\hline$(0,0,0.1)$ & $(0,0.1, .3)$ & $(0.1,0.3,0,5)$ & $(0.3,0.5,0.7)$ & $(0.5,0.7,0.9)$ & $(0.7,0.9,1)$ & $(0.9,1,1)$ \\
\hline
\end{tabular}

Table 2

Linguistic terms for the importance rating along with their relative importance

\begin{tabular}{lllllll}
\hline Very bad(VB) & Bad (B) & Medium bad (MB) & Medium (M) & Medium good (MG) & Good (G) & Very good (VG) \\
\hline$(0,0,1)$ & $(0,1,3)$ & $(1,3,5)$ & $(3,5,7)$ & $(5,7,9)$ & $(7,9,10)$ & $(9,10,10)$ \\
\hline
\end{tabular}

Step 3: Integrate decision makers' preferences and opinions. The decision is derived by aggregating the fuzzy weight of criteria and fuzzy rating of alternatives from $n$ decision-maker calculated,

$$
\tilde{w}_{j}=\frac{1}{n}\left[\sum_{e=1}^{n} \tilde{w}_{j}^{e}\right], j=1,2, \ldots, k
$$

In addition, the preferences and opinions of $n$ decision-maker with respect to $j^{\text {th }}$ criterion for the importance weight of each criterion and the rating of each alternative in the $i^{\text {th }}$ alternative can be calculated as follows,

$$
\tilde{x}_{i j}=\frac{1}{n}\left[\sum_{e=1}^{n} \tilde{x}_{i j}{ }^{e}\right], i=1,2, \ldots, m \quad \tilde{W}=\left[\tilde{w}_{1}, \tilde{w}_{2}, \ldots, \tilde{w}_{k}\right]
$$

Step 4: Calculate fuzzy weighted average and construct the (normalized) fuzzy decision matrix: 


$$
\begin{aligned}
& \begin{array}{ccccc}
C_{1} & C_{2} & \mathrm{C}_{3} & \cdots & C_{k} \\
(\tilde{x} & \tilde{x} & \tilde{x} & \cdots & \tilde{x}
\end{array}
\end{aligned}
$$

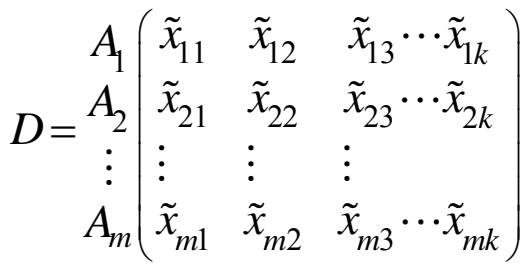

where $X_{\mathrm{ij}}$ is the rating of alternative $A_{\mathrm{i}}$ with respect to criterion $C_{\mathrm{j}}$, and $W_{\mathrm{j}}$ is the important weight of the $j^{\text {th }}$ criterion. This study, therefore, denoted linguistic variables $X_{\mathrm{ij}}$ and $W_{\mathrm{j}}$ as triangular fuzzy numbers.

Step 5: Determine the fuzzy best value (FBV) and fuzzy worst value

$$
\tilde{f}_{j}^{*}=\max _{i} \tilde{x}_{i j}, \tilde{f}_{j}^{-}=\min _{i} \tilde{x}_{i j}
$$

Step 6: Calculate the values:

$$
\frac{\tilde{w}_{j}\left(\tilde{f}_{j}^{*}-\tilde{x}_{i j}\right)}{\left(\tilde{f}_{j}^{*}-\tilde{f}_{j}^{-}\right)}, \quad \tilde{S}_{i}=\sum_{i=1}^{k} \frac{\tilde{w}_{j}\left(\tilde{f}_{j}^{*}-\tilde{x}_{i j}\right)}{\left(\tilde{f}_{j}^{*}-\tilde{f}_{j}^{-}\right)}, \tilde{R}_{i}=\max _{j}\left[\frac{\tilde{w}_{j}\left(\tilde{f}_{j}^{*}-\tilde{x}_{i j}\right)}{\left(\tilde{f}_{j}^{*}-\tilde{f}_{j}^{-}\right)}\right],
$$

where $\tilde{S}_{i}$ and $\tilde{R}_{i}$ represent the utility measure and the regret measure, respectively, and $W_{j}$ is the weight of the $j^{\text {th }}$ criterion (Tong et al., 2005). In fact, $\tilde{S}_{i}$ is $A_{\mathrm{i}}$ with respect to all criteria calculated by the sum of the distance for the FBV, and $\tilde{R}_{i}$ is $A_{\mathrm{i}}$ with respect to the $j^{\text {th }}$ criterion, calculated by the maximum distance of FBV.

Step 7: Calculate the values of $\tilde{S}^{*} ; \tilde{S}^{-} ; \tilde{R}^{*} ; \tilde{R}^{-} ; \tilde{Q}_{i}$ :

$$
\begin{aligned}
\tilde{S}^{*} & =\min _{i} \tilde{S}_{i}, \tilde{S}^{-}=\max _{i} \tilde{S}_{i} \\
\tilde{R}^{*} & =\min _{i} \tilde{R}_{i}, \tilde{R}^{-}=\max _{i} \tilde{R}_{i} \\
\tilde{Q}_{i} & =v \frac{\left(\tilde{S}_{j}-\tilde{S}^{*}\right)}{\left(\tilde{S}^{-}-\tilde{S}^{*}\right)}+(1-v) \frac{\left(\tilde{R}_{j}-\tilde{R}^{*}\right)}{\left(\tilde{R}^{-}-\tilde{R}^{*}\right)}
\end{aligned}
$$

Here, $\tilde{S}^{*}$ is the minimum value of $\tilde{S}_{i}$ which is the maximum majority rule or maximum group utility, and $\widetilde{R}^{*}$ is the minimum value of $\tilde{R}_{i}$ which is the minimum individual regret of the opponent. Thus, the index $\tilde{Q}_{i}$ is obtained and is based on the consideration of both the group utility and individual regret of the opponent. In addition, $v$ here means the weight of the strategy of the maximum group utility (Wu et al., 2009). When $v>.5$, the decision tends towards the maximum majority rule; and if $v=.5$, the decision tends towards the individual regret of the opponent. Hence, $v$ is introduced as weight of the strategy of 'the majority of attributes'. Usually, the value of $v$ is taken as 0.5 . However, $v$ can take any value from 0 to 1(Aghajani Bazzazi et al., 2011). Rank and improve the alternatives, sort by the values $S, R$, and $Q$, in non-increasing order and reduce the gaps in the criteria. The results are three ranking lists, with the best alternatives having the lowest value (Wu et al., 2009).

\section{Numerical Example}

As an example, consider a case where we wish to arrange some of existed models of Nokia cell phone in Iran market and have the best selection by considering its economic situation. After prior assessment, we consider twelve models, which are mostly attended. These models are as below, 
.

We 10 cell phone's experts to rank these models based on different criteria that are including,

1. Beauty and method of design;

2. Quality of voice and resolution;

3. Being a new product;

4. Price;

5. Availability to match with different programs and software;

6. Battery Consumption;

7. Being a compact and small one.

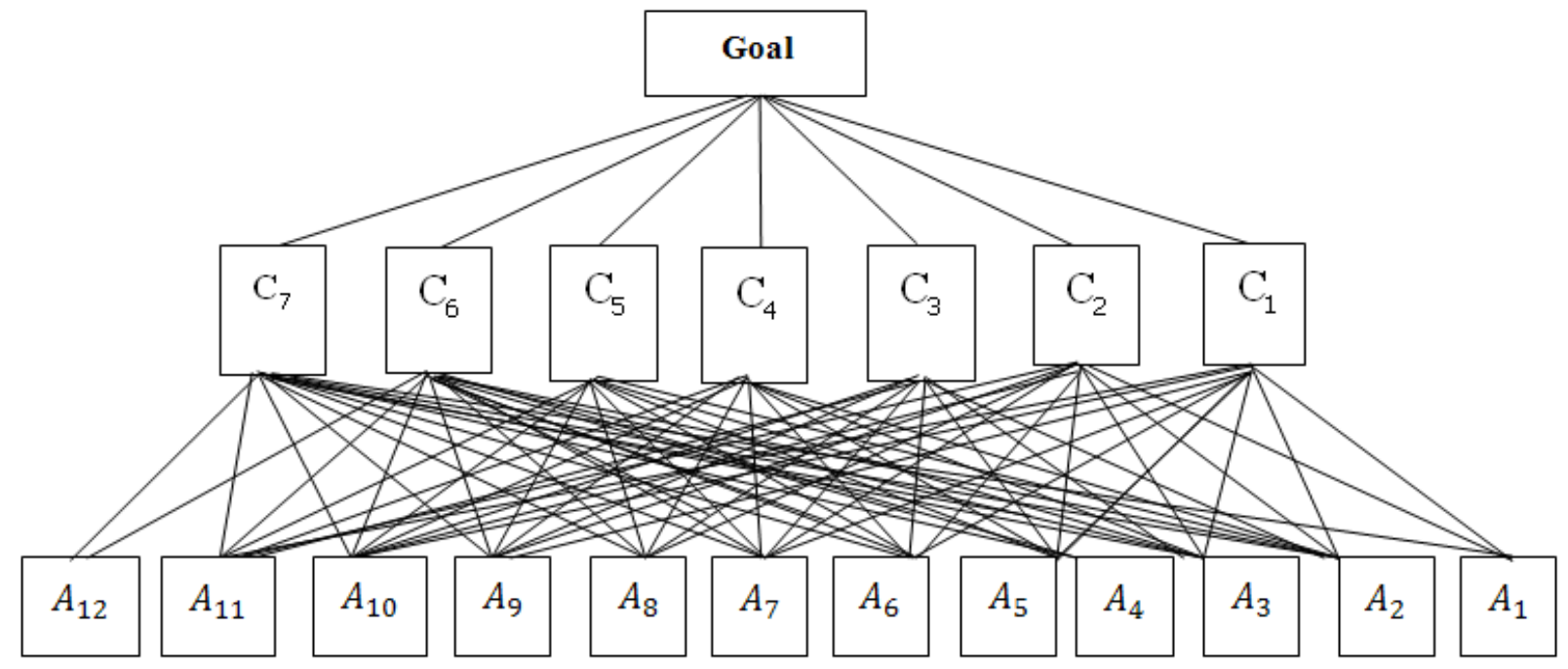

Fig. 3. The general model of evaluation

Now, the suggestive method is used for solving this matter. To determine criteria weight, some questionnaires were sent to the mentioned 10 cell phone experts and professionals whose ideas were influential on product selection. The relative importance of criteria are reported in Table 2.

The decision matrix and weight importance of the criteria have been collected. Table 3 shows details of the calculations for $\tilde{S}_{i}$ and $\tilde{R}_{i}$.

\section{Table 3}

Details of $\tilde{S}_{i}$ and $\tilde{R}_{i}$

\begin{tabular}{|c|c|c|c|c|c|c|c|}
\hline S1 & 3.583079 & 23 & 198.4482 & R1 & 110.4 & 6 & 1.170732 \\
\hline $\mathrm{S} 2$ & 2.866669 & 22.4903 & 193.8385 & R2 & 105.8 & 5.806452 & 1.097561 \\
\hline S3 & 2.33338 & 20.88041 & 152.368 & R3 & 82.8 & 6 & 1.170732 \\
\hline S4 & 2.432238 & 22.3789 & 175.0687 & R4 & 87.4 & 5.806452 & 1.097561 \\
\hline S5 & 3.327781 & 25.36906 & 151.1844 & R5 & 78.2 & 5.419355 & 1.552941 \\
\hline S6 & -3.53343 & -20.7076 & 3.854627 & R6 & 18.4 & 2.264516 & 2.04 \\
\hline S7 & -5.11093 & -22.2676 & -33.6094 & R7 & 13.875 & 1.741935 & 1.88 \\
\hline S8 & -6.21678 & -24.2986 & -42.9399 & $\mathrm{R} 8$ & 12.025 & 1.045161 & 1.94 \\
\hline S9 & -6.0498 & -25.5836 & -51.8265 & R9 & 13.4125 & 1.567742 & 1.88 \\
\hline S10 & -6.42059 & -26.0328 & -20.5597 & R10 & 11.88571 & 0.696774 & 1.98 \\
\hline S11 & -14.3863 & -69.6961 & -247.306 & R11 & 35.65714 & 0 & 3.76 \\
\hline $\mathrm{S} 12$ & -15.0536 & -71.1301 & -262.887 & R12 & 36.57143 & 0 & 3.76 \\
\hline
\end{tabular}


Table 4 shows the maximum and minimum amounts of $\tilde{S}_{i}$ and $\tilde{R}_{i}$

\section{Table 4}

The maximum and minimum amounts of $\tilde{S}_{i}$ and $\tilde{R}_{i}$

\begin{tabular}{cccccccc}
\hline $\mathrm{S}^{*}$ & -15.0536 & -71.1301 & -262.887 & $\mathrm{R}^{*}$ & 11.88571 & 0 & 1.097561 \\
\hline $\mathrm{S}-$ & 3.583079 & 25.36906 & 198.4482 & $\mathrm{R}-$ & 110.4 & 6 & 3.76 \\
\hline
\end{tabular}

Finally, the ranking of all mobile phone models are given as follows,

Table 7

Final ranking of cell phone models

\begin{tabular}{cccccc}
\hline Rank & & Model & \multicolumn{3}{c}{ Fuzzy numbers } \\
\hline 1 & Q12 & N900 & 0.587078 & 5.438737 & 1.67471 \\
2 & Q11 & N86 & 0.680197 & 5.469911 & 1.713968 \\
3 & Q10 & N85 & 1.791766 & 6.419112 & 2.285266 \\
4 & Q8 & N97 & 1.820207 & 6.456812 & 2.228878 \\
5 & Q9 & N96 & 1.843508 & 6.428878 & 2.206488 \\
6 & Q7 & N95 & 1.974522 & 6.500966 & 2.252387 \\
7 & Q6 & 6700 & 2.194655 & 6.534877 & 2.346779 \\
8 & Q3 & N79 & 3.013337 & 7.438966 & 2.720966 \\
9 & Q4 & 5800 & 3.027132 & 7.471542 & 2.778161 \\
10 & Q2 & 5130 & 3.087755 & 7.473963 & 2.825453 \\
11 & Q5 & 6600 & 3.152101 & 7.536545 & 2.717984 \\
12 & Q1 & 6700 & 3.187726 & 7.485044 & 2.837067 \\
\hline
\end{tabular}

Indeed, this is a simple example and is related to a few of examples in the society and it is possible to have different result in other examples. Our aim from this example is to illustrate the suggestive method.

\section{Conclusion}

Totally, theory of fuzzy collection is suitable for the different cases in product selection that are challenging with ambiguous and indefinite data. In a process of decision making, using oral variables in decision matters is more suitable while operational amount cannot be noted by numeral amounts. Regarding experiences of decision makers, conceptual and emotional estimations are often created in the process of product selection.

An advanced method of VIKOR in a fuzzy environment has been suggested in this article. In fact, VIKOR fuzzy method is very flexible. With regard to factor of closeness, not only we can arrange but also we can determine evaluation manners of all products. Systematic frame for product selection in the shown fuzzy environment can be used for other analysis of management decision problems.

\section{References}

Amiri, M., Ayazi S. A., Olfat, L., \& Siahkali Moradi, J. (2011). Group decision making process for supplier selection with VIKOR under fuzzy circumstances. International Bulletin of Business Administration, 10, 62-75.

Aghajani Bazzazi, A., Osanloo, M., \& Karimi, B. (2011). Deriving preference order of open pit mines equipment through MADM method: Application of modified VIKOR method. Expert Systems with Applications, 38, 2550-2556.

Buckley, J. J. (1985). Fuzzy hierarchical analysis. Fuzzy Sets and Systems, 17, 233-247. 
Chen, C.T. (2000). Extensions of the TOPSIS for group decision-making under fuzzy environment. Fuzzy Sets and Systems 114, 1-9.

Chen, L. Y., \& Wang, T.-C. (2009). Optimizing partners' choice in IS/IT outsourcing projects: The strategic decision of fuzzy VIKOR. International Journal of Production Economics, 120(1), 233242.

Choi, T.Y., \& Hartley, J.L. (1996). An exploration of supplier selection practices across the supply chain. Journal of Operations Management, 14(4), 333-343.

Chou, S. Y., \& Chang, Y. H. (2008). A decision support system for supplier selectionbased on a strategy-aligned fuzzy SMART approach. Expert Systems with Applications, 34(4), 2241-2253.

Cook, R. L. (1992). Expert systems in purchasing applications and development. International Journal of Purchasing and Management, 18, 20 -27.

Chu, M.T., Shyu, J., Tzeng, G.H., \& Khosla, R. (2007). Comparison among three analytic method for knowledge communication group decision analysis. Expert Systems with Applications, 33(4), $1011-1024$.

Delgado, M., Verdegay, J.-L., \& Vila, M.A. (1992). Linguistic decision-making models. International Journal of intelligent Systems, 7, 479-492.

Donaldson, B. (1994). Supplier selection criteria on the service dimension. European Journal of Purchasing \& Supply Management, 1(4), 209-217.

Ellram, L.M. (1992). The supplier selection decision in strategic partnerships. International Journal of Purchasing and Management, 18, 8-14.

Ghodsypour, S.H., O'Brien, C. (1998). A decision support system for supplier selection using an integrated analytic hierarchy process and linear programming. International Journal of Production Economics, 56-57, 199-212.

Hwang, C.L., \& Yoon, K.. (1981). Multiple Attributes Decision Making Methods and Applications. Springer, New York.

Kaufmann. A., \& Gupta, M.M. (1991). Introduction to Fuzzy Arithmetic: Theory and Applications. Van Nostrand Rein-hold, New York.

Lee, E.K., Ha, S., Kirn, S.K., \& Delgado, M. (2001). Supplier selection .and management system considering relationships in supply chain management. IEEE Transactions on Engineering Management, 48 (3), 307-318.

Monczkil, R., Trent, R. Handfield, R. (1998). Purchasing and Supply Chain Management. SouthWestern College Publishing, New York.

Opricovic, S. (1998). Multiple criteria Optimization of Civil Engineering Systems, Faculty of Civil Engineering, Belgrade.

Opricovic, S. (2008). A compromise solution in water resources planning. Water resource management, 23, 1549-1561.

Opricovic, S., \& Tzeng, G.H. (2004). Compromise solution by MCDM method: A comparative analysis of VIKOR and TOPSIS. European Journal of Operational Research, 156 (2), 445-455.

Roodhooft, F., \& Konings, J. (1996). Vendor selection and evaluation - an activity based costing approach. European Journal of Operational Research, 96, 97-102.

Sayadi, M. K., Heydari, M., Shahanaghi, K. (2009). Extension of VIKOR method for decision making problem with interval numbers. Applied Mathematical Modeling, 33, 2257-2262.

Swift, C. O. (1995). Preference for single sourcing and supplier selection criteria. Journal of Business Research, 32, 105-111.

Trajkovic, S., Avakumovic, D., \& Opricovic S. (1997). Multi criteria optimization of an irrigation system. Architecture and Civil Engineering, 1(4), 547 - 552.

Tzeng G.H., Lin C.W., \& Opricovic, S. (2005). Multi criteria analysis alternative fuel buses for public transportation. Energy Policy, 33, 1373-1383.

Verma, R., \& Pullman, M.E. (1998). An analysis of the supplier selection process. Omega, 26, 739750 . 
Weber, C.A., Current, J.R., \& Benton, W.C. (1991). Vendor selection criteria and methods. European Journal of Operational Research, 50, 2-18.

Weber, C.A., Current, J.R., \& Desai, A. (1998). Non-cooperative negotiation strategies for vendor selection. European Journal of Operational Research, 108, 208-223.

Wu, H.Y., Tzeng, G.H., \& Chen, Y.H. (2009). A fuzzy MCDM approach for evaluating banking performance based on Balanced Scorecard. Expert Systems with Applications, 36(6), 10135-10147. 